\title{
STUDIES ON SOIL PHYSICS.
}

\section{Part I.-The Flow of Air and Water throvgh Solls.}

BY W. HEBER GREEN, D.Sc., Lecturer and Demonstrator in Chemistry, Oniversity of Melbourne, AND G. A. AMPT, B.So., Victorian Government Research Scholar.

\section{Introduction.}

§1. In connexion with a research on the composition of drainage waters from soils, which is now being undertaken at this laboratory, it was found advisable to have some definite knowledge of the permeability of the soils to water.

The mecbanical analysis of soils, as ordinarily carried out, determines the percentages of the various sized particles present; but this determination in the majority of cases gives only indirect and approximate information as to its properties. For example, we know, in a general way, that a soil containing a large percentage of clay will be only sligbtly permeable to air or water, and conversely, if it be composed mainly of coarse particles, it will usually be open and easily drained; but the presence or absence of humus material may have an altogether indeterminable effect on these properties if we have merely the usual mechanical and chemical analyses to guide us.

In any case such knowledge is at best only qualitative, whereas the information actually required in the above instances-indeed in any investigation dealing with drainage, irrigation or loss by evaporationshould quantitatively express the relations of the soil to the movements of air and water through it.

These relations are much less obscure if we direct our attention to the number and dimensions of the spaces between the particles rather than to the sizes of the particles themselves.

It will be shewn that the information required can be supplied for a given soil by a knowledge of three quantities which may be regarded, and recorded, as speeific constants of the soil. 


\section{§2. Definitions of Soil Constants.}

(a) The Specific Pore or Interstitial Space, designated by $S$, may be defined as the free space per unit volume of soil.

(b) The Permeability to Water, designated by $P_{w}$, may be measured by that volume of- water which will pass per second, through a soil column of unit length and of unit area of cross-section when under one centimetre head of water pressure. The Permeability to Air may be similarly defined and is designated by $P_{a}$.

(c) The Capillarity Coefficient, designated by $K$, may be defined as the tension due to capillary forces per unit area of cross-section of the pore-spaces which tends to draw the water from the saturated to the dry region of the soil.

$\$ 3$. King has indeed suggested the direct measurement of the permeability but he uses the data so obtained to calculate the average size of the soil particles, without insisting on the intrinsic value of the permeability constant itself.

This paper describes our attempts to construct a scientific basis for these three fundamental constants and includes an account of the methods adopted for their measurement and the results obtained with three types of soil.

$\S 4$. These constants are constants for a particular soil in a particular condition; they are however all interdependent, and are liable to considerable alteration when the soil is disturbed as by the ordinary farm operations of ploughing, rolling, etc., or by the ordinary process of taking the sample. Alterations are also caused by variations in the water content.

Obviously, therefore, the measurements should be made on the soil in situ, although our preliminary experiments have been made on " disturbed" samples.

The perfection of a method of soil sampling which will not disarrange the original structure, etc., is greatly to be desired, as it would render possible the comparison of the relative efficiency of various methods of cultivation-to mention one of many applications. An instrument has indeed been devised for this purpose by Stevenson ${ }^{2}$, but the present writers have as yet had no opportunity of testing its suitability for their purpose.

1 Iowa Agric..Expt. Station, U.S.A., Bul. 94, 1908. 


\section{Theoretical Development and Discussion of the Soil Constants.}

$\S 5$. (a) The Specific Pore Space.-The accurate calculation or measurement of this factor is a far from satisfactory problem when complicated by the ordinary field conditions, and both the permeability and the capillarity of the soil shew considerable variations for a small difference in its value.

In the experiments (to be described in a further paper) with practically uniform spherical glass beads of 0.25 to $1.0 \mathrm{~mm}$. diameter, the pore space varied from 0.40 , when the beads were simply poured into the containing vessel, to 0.35 , when they were compacted as far as was possible by rolling and tapping. In the latter state the permeability was found to bave been reduced to about 60 per cent. of its original value.

For soils, the specific pore or interstitial space-i.e. the free space per unit volume of soil-may be considered either as the actual space available for the interstitial air $\left(S_{a}\right)$ or else as the total space not occupied by the solid matter of the soil $\left(S_{w}\right)$. The usually slight difference between these two, in moderately dry laboratory samples, is of course due to the moisture present covering each grain of soil with a thin film of water and cutting down the free space available for air, and

$$
S_{v}=S_{a}+\theta,
$$

where $\theta$ is the volume of water present per c.c. of soil.

- In a wet or waterlogged soil $S_{a}$ may be only a small fraction of $S_{w}$.

In this research the specific pore-space, unless otherwise indicated, bas been taken to mean $S_{a}$.

§6. (b) The Permeability to Air and Water.-We may regard a porous soil as composed of a bundle of capillary tubes, irregular in area, length, direction and shape, but sufficiently minute to reduce the velocity of flow of air or water, under normal conditions, to velocities which conform to Poiseuille's capillary tube law:

$$
v=\frac{\pi}{8}: \frac{g h s t}{\eta} \cdot \frac{r}{l}
$$

$$
\begin{array}{ll}
\text { where } & v=\text { volume of liquid passing in time } t ; \\
\text { and } & =\text { density of liquid; } \\
r & =\text { radius of capillary; } \\
\eta & =\text { viscosity of liguid; }
\end{array}
$$




$$
\begin{aligned}
& l=\text { length of capillary; } \\
& g=\text { gravitational constant; } \\
& h=\text { head of liquid pressure. }
\end{aligned}
$$

But for a soil the capillaries must be treated statistically and $r$ replaced by $\Sigma r^{4}$ to denote the sum of the fourth powers of the efficient average radii of the capillaries in the area of cross-section $A$ under consideration.

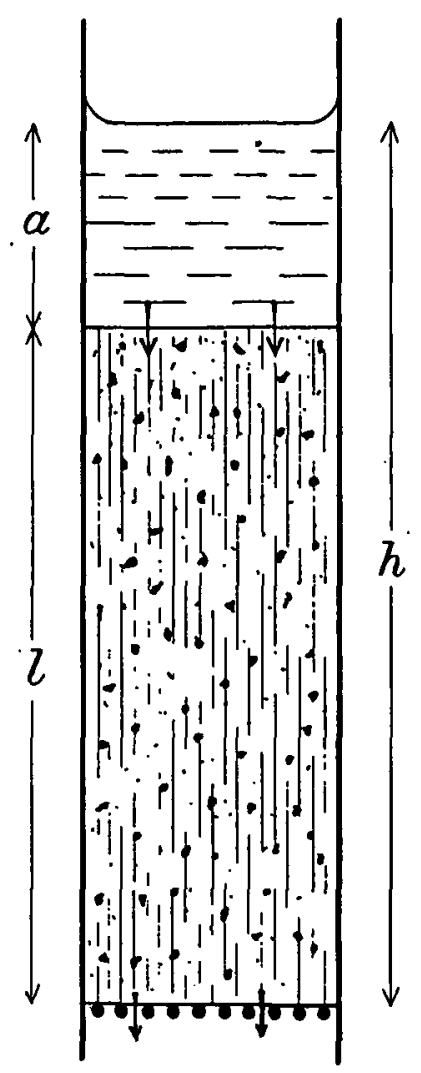

Fia. 1.

If we consider a vertical tube of soil (Fig. 1), of length $l$, through which water is flowing under the influence of a head of pressure $a+l=h$, and escaping freely at the lower end; then

$$
\frac{v}{t}=\frac{\pi}{8 \eta} \cdot \frac{g h s}{l} \cdot \Sigma r^{\prime}
$$


but $v=A x$, where $x=$ the distance that any given cross-section of water (of area $A$ ) has moved in the time $t$; therefore,

$$
\begin{aligned}
\frac{x}{t} & =\frac{\pi}{8 \eta} \cdot \frac{g h s}{l} \cdot \frac{\Sigma r^{-}}{A} \\
& =c \cdot \frac{h}{l} \cdot p,
\end{aligned}
$$

where $c=\frac{\pi g s}{8 \eta}$ and $p=\frac{\Sigma r}{A}$ (the absolute permeability of the soil).

Then

$$
\begin{gathered}
c p=\frac{x}{t} \cdot \frac{l}{h}=P_{w} \\
P_{w}=\frac{v}{t} \cdot \frac{l}{A h}
\end{gathered}
$$

\$7. $P_{w}$ is the practical permeability constant of the soil for water, and is equal to the volume of water passing, in unit time, through a soil column of unit area of cross-section under a head of water pressure equal to the length of the column. It may also be expressed as "the linear rate at which water will sink through an area of soil, saturated and just covered with the water."

Whereas $p$, the absolute permeability, is independent of the temperature and depends only on the structure of the soil, $P$ is inversely proportional to the viscosity of the permeating fluid and therefore, when water is employed, varies some two or three per cent. per degree centigrade.

\$8. In measuring the permeability to air, $P_{a}$, Meyer has shewn that the working pressure $g h s$ in equation (2) must be replaced by $q_{1}-q_{2}$, where $q_{1}, q_{2}$ are the pressures (in absolute units) of air at the two ends of the column, or more correctly by $\frac{q_{1}^{2}-q_{2}^{2}}{q_{0}}$, where $q_{0}$ is the pressure under which the volume $v$ of the air is measured.

Various experimenters, including Darcy (1856), Hazen (1890), King and Slichter (1899), Bell and Cameron (1906) and Leather (1908) have made measurements on the permeability of soils to either air or water and have found that, with certain limitations to be discussed further, both the Poiseuille and Meyer-Poiseuille formulae hold good.

\$. From equation (3) $\eta_{w} P_{w}$ should be equal to $\eta_{a} P_{a}$; or $p$, the absolute permeability, should be independent of the fluid (water or air) experimented with unless the presence of the water is sufficient to modify the capillary passages of the soil. 
A critical examination of the results obtained by $\mathrm{King}^{2}$ and of the measurements to be here described, shew that this modification may take place in two ways: (i) by the moisture in the soil restricting the area of the capillaries through which the air is passing, and hence causing $S_{a}$ to be less than $S_{v}$; and (ii) by the humus, clay or other colloidal matter of the soil absorbing yater when the soil is wet. The consequent swelling may restrict or even completely close the capillaries in this case.

These considerations again emphasise the advisability of determining the permeability to air and water of the soil in situ, without disturbing either its structure or its moisture content.

\$10. (c) The Capillary Coefficient.-Thus far we have considered the permeability of soils to water when they are already saturated, but under ordinary conditions soils are usually less moist than this and may sometimes be almost dry.

Capillary forces must therefore be taken into account, for they assist the hydrostatic pressure when the water is passing downwards and can, in the dry season, even cause moisture to rise to the surface against the force of gravity. The papers of Lyman Briggs, Buckingham and Cameron $^{2}$ and of Leather ${ }^{3}$ are of great interest in this connexion.

To investigate the nature of the capillary constant we will, as before, consider a column of soil uniformly packed in a tube through which water is percolating from one end.

$\S 11$. There are three possible cases for consideration, according as the water is travelling vertically downwards or upwards, or horizontally sideways.

1. Of these three possibilities take first the case in which the movement is vertically downwards.

Then the impelling force at any instant will no longer be ghs as in equation (2) but $g s(h+K)$ where $K$ is a constant of the soil depending on the capillary forces acting on the moving boundary of the water.

As the water only occupies the pore-space, $S$, of the soil it follows that at any stage the velocity of the water front will be given by the equation

$$
\frac{d v}{d t}=A \frac{d l}{d t} S
$$

1 XVth Ann. Rep. Wisc. Agr. Expt. Station, p. 123.

2 U.S.A. Baresu of Soils, Buls. 10, 19, 30, 38, etc.

8 Mem. Dept. Agric. India, 1908, Vol. 1. 79. 
where $v$ and $l$ as before represent respectively the volume of the water and the length of the wetted soil (Fig. 2).

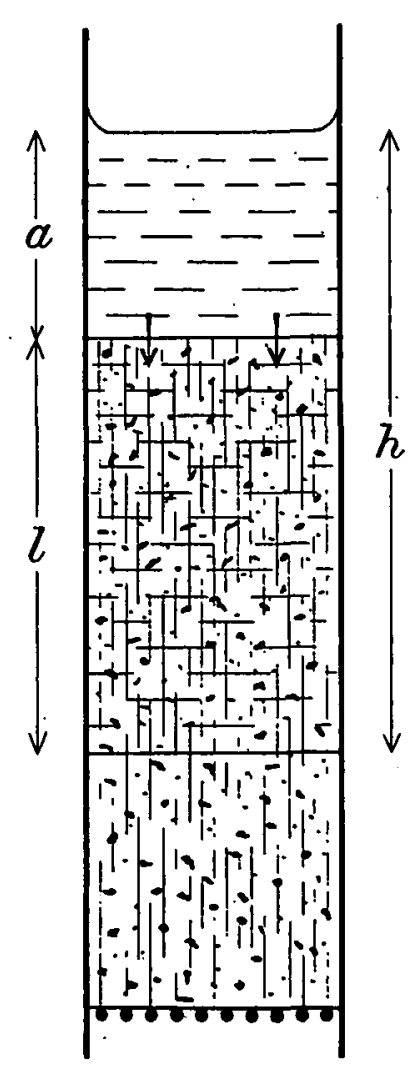

FIG. 2, .

Then on the basis of equation (3), we get

$$
\begin{aligned}
\frac{d l}{d t} & =\frac{\pi}{8 \eta} \cdot \frac{g s(h+K)}{l} \cdot \frac{\Sigma r^{4}}{A S} \\
& =\frac{c p}{S} \cdot \frac{h+K}{l} \\
& =\frac{P}{S} \cdot \frac{h+K}{l} \ldots \ldots \ldots . . .
\end{aligned}
$$

therefore as $h=a+l$, and $a, K, P$ and $S$ are constants,

$$
\frac{P}{S} t=\int_{l}^{0} \frac{l \cdot d l}{l+a+\bar{K}}
$$


and, since $t=0$ when $l=0$,

$$
\frac{P}{S} t=l-(a+K) \log _{e}\left(1+\frac{l}{a+\mathscr{K}}\right)
$$

2. The second possibility comprises the case in which the water is rising vertically in the column of soil, under the influence of capillarity, and against the hydrostatic pressure.

If the lower end be just in contact with the water surface then $h=l$ and $a=0$ and the equation becomes

$$
\frac{d l}{d t}=\frac{P}{S} \cdot \frac{K-l}{l}
$$

which on integration gives

$$
\frac{P}{S} t=K \log _{0}\left(\frac{l}{K-l}\right)-l
$$

3. In the third possibility the motion is horizontal, and in this case is due entirely to capillary suction.

Hence

$$
\frac{d l}{d t}=\frac{P}{S} \cdot \frac{K}{l}
$$

and integrating,

$$
\frac{P K}{S} t=\frac{1}{2} l^{2}
$$

This case is perhaps the most interesting, for not only is it often realized in the field (as when water is percolating from irrigation channels) but its experimental realization in the laboratory can be readily followed without the mathematical and otber complications present in the two first cases.

\$12. Experimental tests of validity and further development of the formulae deduced in $\S 11$.-We have thus deduced three formulae representing the movement of water through dry soil in the three important directions, and the validity of these provisional formulae $(9,11,13)$ has been tested experimentally in the following manner.

$\$ 13$. A glass tube about one inch in diameter and thirty inches long was carefully and uniformly packed with air-dry loam to within six inches of the upper end; the lower end of the tube being closed with a disc of copper gauze supported by a perforated cork. A layer of water $10 \mathrm{cms}$. deep was placed on top of the soil column, and any deficiency caused by percolation of this water into the soil was made good by means of the usual constant level apparatus. 
Readings were taken of the progress of the water downwards at intervals during sixty hours, at the end of which time water began to drip from the lower end of the tube.

From equation (9),

$$
\frac{P}{S}=\frac{l-(a+K) \log _{e}\left(1+\frac{l}{a+K}\right)}{. t} .
$$

$K$ was unknown, but a few trials showed that $K=90$ gave the best results.

The observed values of $l$ were plotted against $t$, and the following results were obtained from the curve drawn through the experimental points :

TABLE I.

\begin{tabular}{|c|c|c|}
\hline$t$ (hours) & $l$ (oentimetres) & $\frac{p}{S}$ \\
\hline $\begin{array}{l}0 \cdot 25 \\
0 \cdot 5 \\
1 \\
2 \\
3 \\
4 \\
5 \\
10 \\
20 \\
50 \\
60\end{array}$ & $\begin{array}{r}3 \cdot 3 \\
4 \cdot 6 \\
6 \cdot 7 \\
9 \cdot 7 \\
11 \cdot 9 \\
14 \cdot 0 \\
15 \cdot 6 \\
21 \cdot 7 \\
31 \cdot 2 \\
52 \cdot 4 \\
58 \cdot 0\end{array}$ & $\begin{array}{l}\cdot 20 \\
\cdot 20 \\
\cdot 206 \\
\cdot 210 \\
\cdot 227 \\
\cdot 225 \\
\cdot 218 \\
\cdot 208 \\
\cdot 202 \\
\cdot 206 \\
\cdot 204\end{array}$ \\
\hline
\end{tabular}

$\S 14$. The same concordance was not obtained, however, when equation (11) was applied by us to a series of measurements carried out by Loughridge ${ }^{2}$ on the rate of rise of water in a tube of soil.

In this case $K$ was taken as $42 \cdot 5$, for that was the maximum height reached by the ascending water.

By equation (11),

$$
\frac{K \log _{\diamond}\left(\frac{K}{K-l}\right)-l}{t}=\frac{P}{S}=\text { a constant } ;
$$

but the actual values calculated from the experimental readings shew that there is some factor which has not been taken into account.

Hilgard, Soils, p. 205. 
TABLE II.

\begin{tabular}{|c|c|c|}
\hline$t$ (hours) & $l$ (centimetres) & $\frac{K \log \left(\frac{K}{K-l}\right)-l}{t}$ \\
\hline & & \\
\hline 1 & $20 \cdot 4$ & $7 \cdot 4$ \\
2 & $25 \cdot 5$ & $6 \cdot 75$ \\
6 & 31 & $4 \cdot 1$ \\
12 & 33 & $2 \cdot 55$ \\
24 & $35 \cdot 7$ & $1 \cdot 75$ \\
48 & 39 & 1.40 \\
$i 144$ & 42.5 & - \\
\hline
\end{tabular}

$\$ 15$. In these calculations the water has been regarded as at once occupying the whole of the pore-space in each layer of the soil as it reaches it. This condition is apparently realised in the case of a downward flow of water; but when the percolation is upward or horizontal numerous experimenters have shewn that the percentage of moisture in the soil decreases continuously with the distance from the water supply.

The same difficulty has been recognised by Bell and Cameron', who have also investigated the rate of entry of water into capillary spaces. They found that for a single horizontal capillary tube the velocity of movement is in accord with equation (13),

$$
\frac{l^{2}}{t}=C,
$$

but for soils and other porous media the rate of movement of the visible water front could only be empirically represented by the equation,

$$
\frac{l^{n}}{t}=C^{\prime},
$$

where $n$ is generally greater than 2 but varies for each individual experiment.

They say: "In this latter case, however, there is no way of distinguishing between that portion of the substance which is merely wet by a capillary film of liquid over the grains or fibres, and that portion of the substance whose interstices are filled with the liquid."

$\$ 16$. If, however, instead of modifying the foregoing equation by empirically altering $n$, it is modified in such a way as to take into account the fact that the length of moistened soil does not correspond

2 Jour. Phys. Chem. 1906, x. 663. 
with the real length of column traversed by the whole of the water, but is greater than this; then the difficulty will be found to disappear.

Consider the case of a horizontal soil column (in order to eliminate all but capillary forces), then the distribution of water will : be as diagrammatically illustrated in Fig. 3 , the foremost portion of the moist area being incompletely saturated and $\theta / s$, the fraction of the soil pores occupied by water, being less than unity.

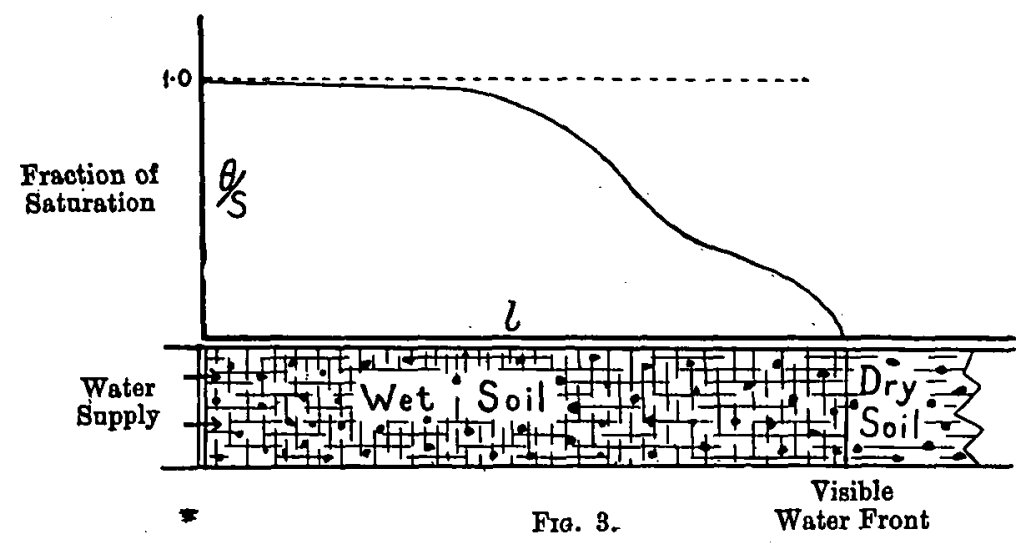

If we assume that the water present in this region is distributed uniformly among the fine and coarse capillaries then the average effective length of the soil column will be equal to $\frac{v}{A S}$, the volume of water which has entered the tube per unit area of cross-section of the soil pores. But $\frac{v}{A S}=\frac{m}{s A S}$ where $m=$ the mass of water absorbed by the soil column, and $s=$ density of water $=1$ (with sufficient accuracy).

Substituting this quantity for $l$ in equation (13), $\frac{2 K P}{S}=\frac{l^{1}}{t}$, we obtain .

$$
2 A^{2} K P S=\frac{m^{2}}{t}
$$

which should, even though not rigidly correct, give us a close approximation to the truth.

The following measurements were taken of both the rate of linear flow and the weight of water percolating into a soil tube: 
TABLE III.

\begin{tabular}{|c|c|c|c|}
\hline$t$ (hours) & $\frac{l^{2}}{t}$ & $\frac{m^{2}}{t}$ & $\frac{\theta}{S}$ \\
\hline 1 & $61 \cdot 3$ & $25 \cdot 3$ & $\cdot 804$ \\
2 & $56 \cdot 9$ & $25 \cdot 9$ & $\cdot 848$ \\
3 & $55 \cdot 5$ & $26 \cdot 0$ & $\cdot 860$ \\
6 & $53 \cdot 9$ & $26 \cdot 3$ & $\cdot 877$ \\
9 & $52 \cdot 3$ & $26 \cdot 3$ & .890 \\
12 & $49 \cdot 0$ & $25 \cdot 9$ & $\cdot 915$ \\
18 & $48 \cdot 5$ & $25 \cdot 7$ & $\cdot 915$ \\
21 & $48 \cdot 0$ & $25 \cdot 7$ & $\cdot 915$ \\
24 & $48 \cdot 1$ & $25 \cdot 9$ & .923 \\
26 & $48 \cdot 3$ & $26 \cdot 0$ & .923 \\
\hline
\end{tabular}

The superiority of equation (14) over equation (13) is conclusively shewn; the values of $\frac{l^{2}}{t}$ and of $\theta / s$ (the fraction of the pore-spaces of the wet soil filled with water) are such as would be expected from the foregoing considerations. The slight rise shewn in the later values of $\frac{l^{2}}{t}$, and less markedly of $\frac{m^{2}}{t}$, has been observed in almost every experiment, and may be accounted for by the effect of the viscosity of air, which steadily diminishes as the tube becomes filled with water.

$\S 17$. The constancy of $\frac{m^{2}}{t}$ as given in Table III. justifies the conclusion that the determination of the weight of water entering a horizontal soil column will lead us to a reliable and sufficiently accurate method of measuring $K P_{w} S$, and since $S$ and $P_{v}$ for the same column of soil can be determined independently, $K$ can be evaluated by substituting their values in equation (14),

$$
2 A^{2} K P_{w} S=\frac{m^{2}}{t}
$$

\section{Experimental Investigation.}

$\S 18$. The soils used.-Three soils were used in these preliminary experiments.

A. A friable loam obtained from the grounds of the University of Melbourne, prepared by breaking up with a rubber pestle. It was spread out on paper to dry, when it was passed through a sieve of about $0.5 \mathrm{~mm}$. mesh-the coarse grains and rootlets, etc, being rejected. 
The moisture content of this air-dried loam was found to be 1.41 per cent. Its density was determined by weighing in a 50 c.c. specific gravity bottle with kerosene $\left(d 1 \frac{8}{8}=0.7993\right)$.

$9 \cdot 796$ grams of air-dry soil. displaced 3.072 grams of kerosene and therefore had a specific gravity of 2.496 . Similarly 14.851 grams of the same soil dried at $100^{\circ} \mathrm{C}$. displaced 4.756 grams kerosene and had a specific gravity of 2.549 . This observed difference is exactly that calculated from the water content of the air-dry soil.

B. A clay soil obtained from Werribee, Victoria, for use in a series of experiments in connexion with the influence of fertilizers on drainage.

This soil was only used in a few experiments.

C. A surface sand obtained from Canterbury, near Melbourne, which was sufficiently free from colloidal clay to serve as a type of a highly permeable soil.

$\S 19$. Method of experimenting.-For the purpose of experiment glass tubes were filled as uniformly as possible with the soil.

The difficulties involved in packing tubes with soil are well known and there is no satisfactory method of determining with what uniformity a tube of soil has been packed. Even two tubes having the same permeability may be very dissimilar in respect to the actual arrangement of the particles of soil.

The method of filling employed in these experiments is as follows: The end of the tube is first temporarily closed with a cork, then about two inches length of soil introduced at a time, and the tube rotated rapidly around its longitudinal axis and occasionally "dumped": too much jarring causes a visible separation of the smaller from the larger particles. In this manner the tube is filled; the other cork is then pressed home, and alternate.rotation and jarring continued until there is no further sign of closer packing. These temporary corks are now removed and the soil is kept in position by accurately fitting discs of filter paper and fine copper gauze backed up by perforated cork plugs carrying glass connecting tubes. Finally the corks and tubes were sealed in position with ceresin or parafin wax as in Fig. 4.

Direct measurements shewed that the resistance offered by the discs of filter paper and gauze was negligible compared with that of a few centimetres of soil.

$\S 20$. In the first experiment, the results of which have already been given in Table III., the tube used had a mean diameter of $3 \cdot 23 \mathrm{~cm}$. and was filled to a length of $58 \mathrm{~cm}$. 
As the amount of soil introduced into the tube was not weighed it was impossible to calculate the pore-space $S$ and so obtain an exact value for $P$, but it will be observed that the water had reached the lower end of the tube in 60 hours.

A similar tube was at the same time filled with the clay soil. Here the downward progress of the water was at first rapid, but after a few minutes became extremely slow, and the advancing line of moisture shewed less and less distinctly until it was eventually practically invisible. An indication was however obtainable that the water had reached the lower end of the column in about eleven months; this gives an approximate idea of the relative permeabilities of the loam and the clay.

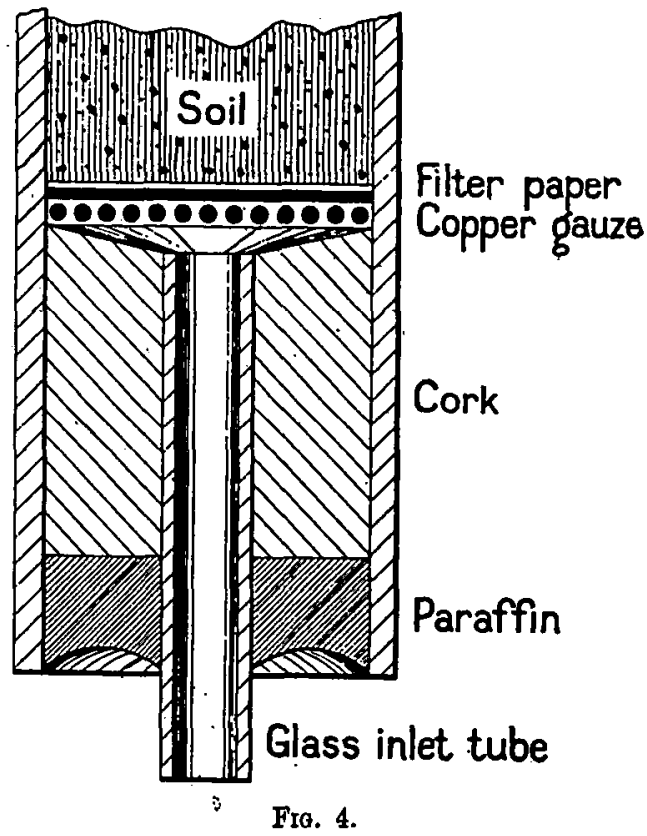

$\therefore$ 21:.. Procedure recommended for the "physical examination" of soils.-In later experiments weighings were taken not only of the soil used but also of the water absorbed, and the following method of procedure was adopted for the "physical examination" of soils:

§22. (1) Determination of the Specific Pore-Space (\$).-The soil was filled into the tube in the manner described, and weighed; the length $(l)$ of the soil column was then measured and from the area of cross-section $(A)$ of the tube (previously determined from the water 
content of a convenient length), and from the specific gravity of the soil, the value of $\$$ can be calculated.

$$
S=1-\frac{W}{A l \Delta},
$$

where $W$ is the weight and $\Delta$ the specific gravity of the soil.

The value of $S$ affords interesting information as to the degree of compactness to which it is possible to pack the soil under the uniform conditions described.

§ 23. (2) Determination of Permeability to Air.-The soil tube is now attached by a short caoutchouc tube to an ordinary nitrometer containing water instead of mercury. An inoreased or diminished pressure can be obtained by appropriate adjustment of the water level in the two limbs and thus air may be forced through the soil tube in either direction.

Both pressure and suction are employed and the times of passage of certain volumes of air, as measured on the nitrometer scale, observed.

It is obvious that the pressure is constantly altering, but the relationship between the pressure (difference in levels) and the volume (indicated by the scale reading) is easily established for $h=h_{0} \pm b v$, where $h_{0}$ is the initial pressure and $b$ is a constant for the particular nitrometer tubes employed.

From equation (5),

$$
P_{a}=\frac{d v}{d t} \cdot \frac{l}{A h},
$$

and as $h=h_{0} \pm b v$, then on integrating between the limits $h_{1}$ and $h_{2}$, i.e. $t_{1}$ and $t_{1}$; we get

$$
\begin{aligned}
P_{a} & =\frac{\log _{e}\left(\frac{h_{1}}{h_{2}}\right) \cdot l}{\left(t_{2}-t_{1}\right) A b} \\
& =\frac{2 \cdot 303 l}{A . b} \cdot \frac{\log _{10}\left(\frac{\dot{h_{1}}}{h_{2}}\right)}{t_{2}-t_{1}}
\end{aligned}
$$

The question as to whether concordant results could be obtained with either "head" or "tail" of pressure was conclusively answered by the following set of readings; and any corrections, such as are required when dealing with a single capillary tube (or higher pressures), are shewn to be unnecessary with ordinary soils for the low pressures used. 
TaBle IV.

Permeability of Soil to Air.

\begin{tabular}{|c|c|c|c|c|c|c|c|}
\hline \multicolumn{4}{|c|}{ Using " head" of pressure } & \multicolumn{4}{|c|}{ Using "tail" of pressure } \\
\hline $\begin{array}{l}v \\
\text { (c.c. of } \\
\text { air) }\end{array}$ & $\stackrel{t}{\text { (minutes) }}$ & $\begin{array}{c}h \\
\text { (cm. of } \\
\text { water) }\end{array}$ & $\frac{\log _{10}\left(\frac{h_{0}}{h}\right)}{t}$ & $\begin{array}{l}\text { (c.c. of } \\
\text { gir) }\end{array}$ & (minutes) $^{t}$ & $\begin{array}{c}h \\
\text { (cm. of } \\
\text { water) }\end{array}$ & $\frac{\log _{10}\left(\frac{h_{0}}{h}\right)}{t}$ \\
\hline $\begin{array}{r}0 \\
2 \\
6 \\
9 \\
10 \\
12 \\
13 \\
14 \\
15 \\
16\end{array}$ & $\begin{array}{c}0 \\
\cdot 51 \\
1 \cdot 70 \\
2 \cdot 88 \\
3 \cdot 81 \\
4 \cdot 38 \\
5 \cdot 00 \\
5 \cdot 71 \\
6 \cdot 56 \\
7 \cdot 58\end{array}$ & $\begin{array}{r}+32.2 \\
29.0 \\
22.7 \\
17.9 \\
14.8 \\
13.2 \\
11.7 \\
10.1 \\
8.5 \\
6.9\end{array}$ & $\begin{array}{l}\overline{-0892} \\
.0893 \\
.0885 \\
.0885 \\
.0884 \\
.0879 \\
.0882 \\
.0882 \\
.0883\end{array}$ & $\begin{array}{r}0 \\
2 \\
5 \\
7 \\
11 \\
12 \\
13 \\
14 \\
15\end{array}$ & $\begin{array}{c}0 \\
\cdot 55 \\
1 \cdot 52 \\
2 \cdot 28 \\
4 \cdot 32 \\
4 \cdot 99 \\
5 \cdot 79 \\
6 \cdot 76 \\
7 \cdot 89\end{array}$ & $\begin{array}{r}-30.0 \\
26 \cdot 8 \\
22.0 \\
18.8 \\
12.5 \\
10 \cdot 9 \\
9.3 \\
7 \cdot 7 \\
6.1\end{array}$ & $\begin{array}{l}-\overline{0891} \\
.0886 \\
.0889 \\
.0880 \\
.0881 \\
.0878 \\
.0874 \\
.0877 \\
-\end{array}$ \\
\hline . & & Average.. & .0885 & & & & 0002 \\
\hline
\end{tabular}

But by taking $h_{1}$ and $t_{1}$ as the initial pressure and time in each calculation any error at that point will affect every observation, and so in later experiments a fresh starting point was taken for each calculation.

$\S 24$. A more convenient and accurate arrangement of apparatus was also devised in which the graduated limb of the nitrometer was replaced by an inverted burette with a two-way tap and the other limb by a large water reservoir. The pressure corresponding to any burette reading is given by the difference in level of the water in the burette and in a short gauge tube of the same diameter attached to the connecting tube by a T-piece. (See Fig. 5.)

In order to avoid inconveniently long or short times of flow the diameter or length of the tube used to contain the soil should be selected to suit its permeability.

The water level is first adjusted to the 25 c.c. mark on the burette with the tap open to the air, and then by applying suction the level is raised several centimetres above the 50 c.c. mark. The tap is then turned to communicate with the soil tube, and the stop-watch started as the water passes the 45 c.c. mark and time readings taken over a range of 15 c.c. when the watch is stopped at the 30 c.c. mark.

Similarly a set of readings are taken between the 5 and 20 c.c. 
marks, when the air will be drawn through the soil tube under a "tail" of pressure.

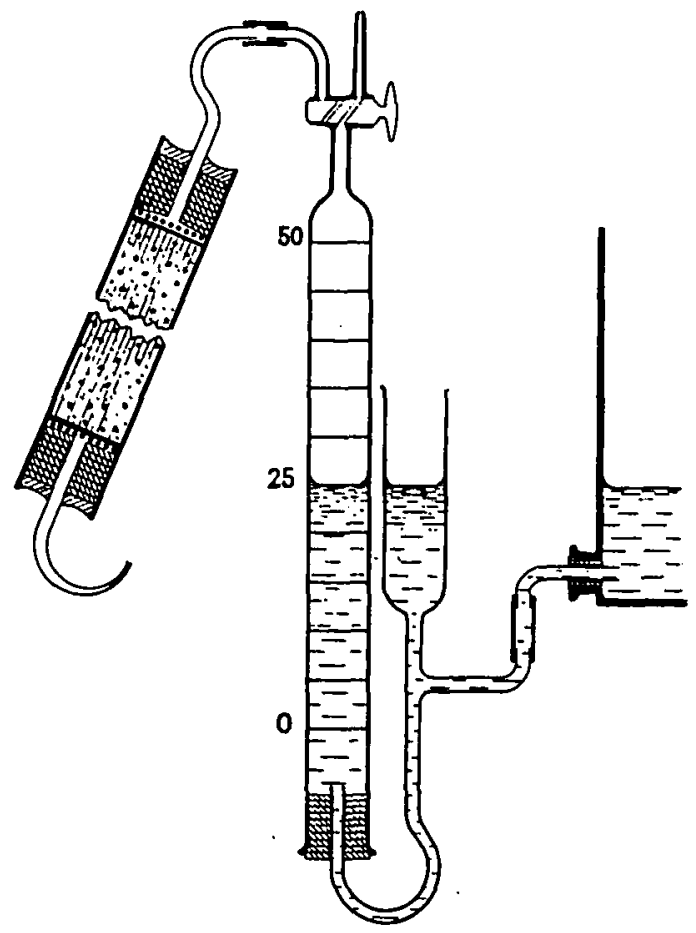

Fia. 5.

The observations recorded in Table V. were taken with both "head" and "tail" of pressure on a tube filled with loam.

Although values of $\frac{\delta v}{\delta t} \cdot \frac{1}{h}$ and consequently of $P_{a}$ can be obtained by taking the differences between consecutive readings in this way, a more systematic method of utilizing such a series of observations is that given in Table VI. As the values of $\log _{10}\left(\frac{h_{1}}{\bar{h}_{2}}\right)$ have only to be determined once for each apparatus, this method of calculation is probably the simplest in practice and certainly the most satisfactory.

Considering the probable calibration errors of an ordinary nitrometer (such as was employed in these experiments) the accuracy of this method of determining the permeability of a column of soil is beyond criticism and the simplicity of the apparatus and measurements 
required give it an important advantage over the methods usually employed for that purpose.

Table V.

Calculation of Permeability Constant from Experimental Results.

\begin{tabular}{|c|c|c|c|c|c|}
\hline \multirow{2}{*}{$v(\mathrm{c.c})}$. & \multicolumn{3}{|c|}{$t$ (minutes) } & \multirow{2}{*}{$h(\mathrm{~cm})$} & \multirow{2}{*}{$\frac{\delta v}{\delta t} \cdot \frac{1}{h}$} \\
\hline & Head & Tail & Mean & & \\
\hline \multirow[t]{2}{*}{$\begin{array}{r}0 \\
2 \\
4 \\
4 \\
5 \\
6 \\
7 \\
8 \\
9 \\
10 \\
11 \\
12 \\
13 \\
14 \\
15\end{array}$} & $\begin{array}{l}\quad 0 \\
.600 \\
1 \cdot 265 \\
1 \cdot 63 \\
2 \cdot 03 \\
2 \cdot 44 \\
2 \cdot 89 \\
\mathbf{3} \cdot 38 \\
3 \cdot 925 \\
4 \cdot 51 \\
5 \cdot 16 \\
5 \cdot 89 \\
6 \cdot 75 \\
7 \cdot 71\end{array}$ & $\begin{array}{l}\quad 0 \\
-590 \\
1.260 \\
1.63 \\
2 \cdot 01 \\
2 \cdot 43 \\
2 \cdot 90 \\
3 \cdot 40 \\
3.925 \\
4.55 \\
5 \cdot 23 \\
6.02 \\
6.91 \\
8.02\end{array}$ & $\begin{array}{l}\quad 0 \\
\cdot 595 \\
1 \cdot 263 \\
1 \cdot 63 \\
2 \cdot 02 \\
2 \cdot 435 \\
2 \cdot 895 \\
3 \cdot 39 \\
3 \cdot 925 \\
4 \cdot 53 \\
3 \cdot 195 \\
5 \cdot 955 \\
6 \cdot 83 \\
7 \cdot 865\end{array}$ & $\begin{array}{r}31 \cdot 68 \\
28 \cdot 52 \\
25 \cdot 35 \\
23 \cdot 77 \\
22 \cdot 19 \\
20 \cdot 36 \\
19 \cdot 01 \\
17 \cdot 42 \\
15 \cdot 84 \\
14 \cdot 26 \\
12 \cdot 67 \\
11 \cdot 09 \\
9 \cdot 50 \\
7 \cdot 92\end{array}$ & $\begin{array}{l}0.1116 \\
0.1111 \\
0.1110 \\
0.1117 \\
0.1127 \\
0.1098 \\
0.1109 \\
0.1124 \\
0.1099 \\
0.1118 \\
0.1107 \\
0.1111 \\
0.1109\end{array}$ \\
\hline & & & & Average... & 0.1112 \\
\hline
\end{tabular}

$$
P_{a}=\frac{l}{A .60} \cdot \frac{\delta v}{\delta t} \cdot \frac{1}{h}=\frac{35 \cdot 05 \times \cdot 1112}{1 \cdot 950 \times 60}=0.0333
$$

TABLE VI.

Calculation of Permeability Constant from Experimental Results.

\begin{tabular}{|c|c|c|c|c|c|}
\hline$v_{1} \quad v_{2}$ & $t_{1}$ & $t_{2}$ & $t_{2}-t_{2}$ & $\log _{10}\left(\frac{h_{1}}{h_{2}}\right)$ & $\frac{\log _{10}\left(\frac{h_{1}}{h_{2}}\right)}{t_{2}-t_{1}}$ \\
\hline $\begin{array}{l}0-9 \\
2-10 \\
1-11 \\
5-12 \\
6-13 \\
7-14 \\
8-15\end{array}$ & \begin{tabular}{l}
\multicolumn{1}{c}{0} \\
0.595 \\
1.263 \\
1.63 \\
2.02 \\
$2 \cdot 435$ \\
2.895
\end{tabular} & $\begin{array}{l}\cdot 3 \cdot 390 \\
3 \cdot 925 \\
4 \cdot 53 \\
5 \cdot 195 \\
5 \cdot 955 \\
6 \cdot 83 \\
7 \cdot 865\end{array}$ & $\begin{array}{l}3 \cdot 390 \\
3 \cdot 330 \\
3 \cdot 287 \\
3 \cdot 565 \\
3 \cdot 935 \\
4 \cdot 395 \\
4 \cdot 970\end{array}$ & $\begin{array}{l}\cdot 2597 \\
\cdot 2554 \\
\cdot 2499 \\
\cdot 2732 \\
\cdot 3012 \\
\cdot 3953 \\
\cdot 3803\end{array}$ & $\begin{array}{l}.0764 \\
.0766 \\
.0763 \\
.0764 \\
.0765 \\
.07623 \\
.0766\end{array}$ \\
\hline & & & & Average... & .07643 \\
\hline
\end{tabular}

$$
P_{a}=\frac{2 \cdot 303 l}{60 . A b} \cdot \frac{\log _{10}\left(\frac{h_{1}}{h_{2}}\right)}{t_{2}-t_{1}}=\frac{2 \cdot 303 \times 35.05 \times \cdot 07643}{60 \times 1.950 \times 1.585}=\cdot 03325
$$


§25. (3) Measurement of Capillary F'low.-The tube is now placed in a horizontal position with the sickle-shaped inlet tube dipping into a dish of water, the surface of which is adjusted to the same level as the axis of the soil column.

A slight suction is now applied at the far end so as to fill the inlet tube with water. Percolation immediately starts and its progress is measured at convenient intervals by weighing the soil tube rapidly and keeping it in the horizontal position so as not to interfere with the percolation.

The distance to which the visible water front has penetrated may also be measured, several readings being taken to obtain its mean position when its progress on different sides of the tube is irregular, as is the case when the packing is not uniform.

TABLE VII.

Calculation of Capillary Constants from Experimental Results.

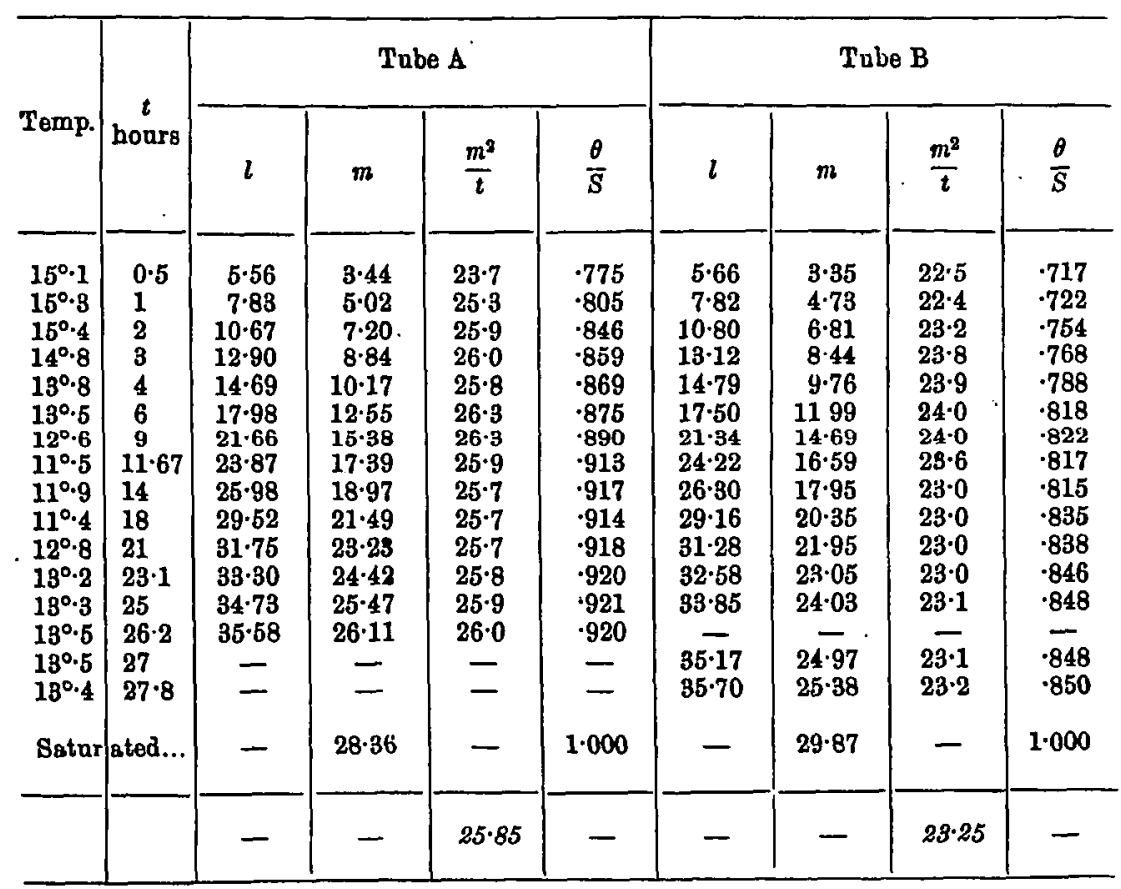

Tube A. KPS $=\frac{m^{2}}{t} \cdot \frac{1}{2 d^{2}}=\frac{25 \cdot 85}{3600 \times 2 \times(1 \cdot 950)^{2}}=0.000944$.

Tube B. $\quad K P S=\frac{m^{2}}{t} \cdot \frac{1}{2 d^{2}}=\frac{23.25}{3600 \times 2 \times(1.962)^{2}}=0.000838$. 
These measurements of $l$ are not required for the calculation of $K$, but are of interest as shewing the distribution of water in the "wet". soil.

$\S 26$. The experiments detailed in Table VII. were carried out simultaneously on two tubes filled with loam in slightly different states of compactness, and illustrate the degree of accuracy to be expected.

The small discrepancies in the values of $\frac{m^{2}}{t}$ can be largely accounted for by the effect of changes of temperature ${ }^{1}$ on the viscosity of the percolating water; another possibility of slight error is the uncertainty in the initial readings and the correction for capacity of the inlet tube.

The figures in the columns headed $\frac{\theta}{S}$ denote the fractional saturation of the wetted portion of the soil. Both tubes had been as uniformly and similarly packed as possible, but the difference in the observed values of $K P S$ is quite appreciable-0.00094 and 0.00084and is due to the different values of $S-0.475$ and 0.4635 .

\$27. (4) Saturation of the Soil in the Tube-After the whole soil column has become wetted the tube is turned up and the inlet (at the lower end) connected with a reservoir of water kept at a higher level than the top of the soil. After some time water begins to flow from the upper end of the soil, and, the outlet having been bent over and drawn out somewhat, this issuing water can be collected and weighed or measured without loss.

Weighings of the tube are made from time to time until no further increase is observed. This gives the amount of water required to saturate the soil and enables a comparison to be made with the value of $S$ as determined in $\$ 22$ from the volume and weight of the soil column. The discrepancy usually found is due to incomplete expulsion of the air from the interstices of the soil.

\$28. (5) Measurement of Permeability to Water.-The - water reservoir is now adjusted at a convenient height above the level of the outlet from the soil tube and the permeability of the soil to water $\left(P_{w}\right)$ calculated from the rate of flow.

$$
P_{w}=\frac{v}{t} \cdot \frac{l}{A h}
$$

I Recently some experiments have been osrried out on tubes kept in a draughtcupboard whose temperature was maintained at $20^{\circ}$ by means of a gas burner and thermostat. The values obtained for $\frac{m^{2}}{t}$ shewed the expected improvement. 
The usual method of measuring permeability is to measure the downward flow, but the rate of flow under these conditions constantly decreases on account of the silting which takes place with ordinary soils. In one tube, the rate of flow became practically zero at the end of three months. This difficulty is overcome by causing the water to flow upwards through the soil and by only employing moderate pressures.

The figures given in Table VIII. were those actually obtained from two different tubes of similar soil.

\section{TABLE VIII.}

Comparison of Upward and Downward Flow of Water for Measurement of Permeability.

\begin{tabular}{|c|c|c|c|}
\hline Downward Flow & Pressure $=76.6 \mathrm{om}$. & Upward Flow. & Pressur $\theta=20 \mathrm{~cm}$. \\
\hline Time & Rate per hour & Time & Rate per hour \\
\hline $\begin{array}{c}1 \text { hour } \\
4 \frac{1}{2} \text { hours } \\
21 \quad ", \\
68 \quad " \\
90 \quad " \\
390 \quad "\end{array}$ & $\begin{array}{l}7 \cdot 85 \text { c.c. } \\
5 \cdot 70 \quad " \\
3 \cdot 49 \quad " \\
2 \cdot 47 \quad " \\
-80 ", \\
-09 ",\end{array}$ & $\begin{array}{l}7 \text { hours } \\
21 " ~ \\
67 " \\
96 "\end{array}$ & $\begin{array}{l}0.32 \text { c.c. } \\
0.32 \quad " \\
0.30 \quad ", \\
0.28, "\end{array}$ \\
\hline
\end{tabular}

§29. (6) Statement of results.-Having thus measured $S, P_{w} K S$ and $P_{w}$ directly, $K$ can be calculated and the three important constants $\left(S, P_{w}\right.$ and $K$ ) controlling the flow of water through the soil should be tabulated.

The structure of its pore-spaces is more definitely described in this way than by any enumeration of the percentages of the various sized particles of which it consists.

$\S 30$. The permeability to air should also be tabulated, as on it depends the natural aeration of the soil, and in this connexion a further important relation is given by $\frac{\eta_{a} P_{a}}{\eta_{10} P_{w}}$. This ratio of the intrinsic permeabilities of soil to air and to water depends on the colloidal matter present and will vary from unity for a clean sand to fourteen or more for a clay soil packed as described above. 
Experimental Results for Three Typical Soils.

$\S 31$. A number of experiments were carried out on these lines on each of the three soils described above and the results tabulated in Tables IX. and X.

Table IX.

The variation of Permeability with Specific Pore-space.

\begin{tabular}{|c|c|c|c|c|c|}
\hline No. & Soil & Condition & $\theta$ & $S$ & $\boldsymbol{P}_{\mathfrak{a}}$ \\
\hline $\begin{array}{l}1 \\
2 \\
3 \\
3 \\
4 \\
5 \\
6 \\
7 \\
8 \\
9 \\
10 \\
11 \\
12 \\
13 \\
14 \\
15 \\
16 \\
17 \\
18 \\
19 \\
20 \\
21 \\
22 \\
23 \\
24 \\
25 \\
26 \\
27\end{array}$ & $\begin{array}{c}\text { A. University Loam } \\
\text { ", } \\
\text { ", } \\
\text {." } \\
\text { B. Werribee Clay } \\
\text { ", } \\
\text { C. Canterbury Sand } \\
\text { ", } \\
\text { ", } \\
\text { ", } \\
\text { ", } \\
\text { ", } \\
\text { ", }\end{array}$ & 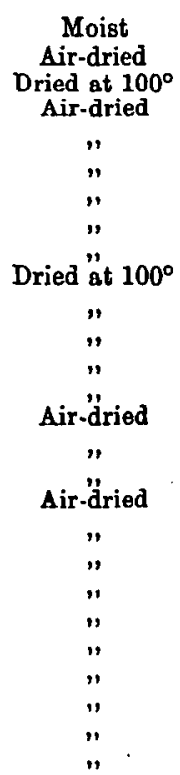 & $\begin{array}{l}.064 \\
.020 \\
.0184 \\
.0192 \\
.0192 \\
.0193 \\
.0194 \\
.0196 \\
= \\
= \\
.0302 \\
.0303 \\
.0305 \\
.0050 \\
" \\
" \\
", \\
", \\
" . \\
", \\
"\end{array}$ & $\begin{array}{l}\cdot 493 \\
\cdot 445 \\
\cdot 412 \\
-490 \\
\cdot 467 \\
\cdot 466 \\
\cdot 468 \\
\cdot 461 \\
\cdot 454 \\
\cdot 495 \\
\cdot 478 \\
\cdot 475 \\
\cdot 467 \\
\cdot 4635 \\
\cdot 431 \\
\cdot 428 \\
\cdot 423 \\
\cdot 379 \\
\cdot 378 \\
\cdot 373 \\
\cdot 373 \\
\cdot 372 \\
\cdot 368 \\
.367 \\
\cdot 363 \\
\cdot 363 \\
\cdot 362\end{array}$ & 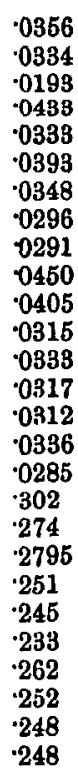 \\
\hline
\end{tabular}

Both the pore-space $(S)$ and permeability $\left(P_{a}\right)$ in Experiments 13 in Table IX. show clearly the effect of moisture on the packing of a soil.

The dependence of the permeability on the specific pore-space is clearly shown by Experiments 4-9, 10-14 and 18-27 in the same Table.

It will there be seen that the specific pore-space is not the only controlling factor, for the discrepancies are greater than can be accounted for by experimental error. This same phenomenon was also noticed in measurements on spherical glass beads, and it would appear that the system of arrangement of the particles has some influence on 
W. Heber Green and G. A. Ampt

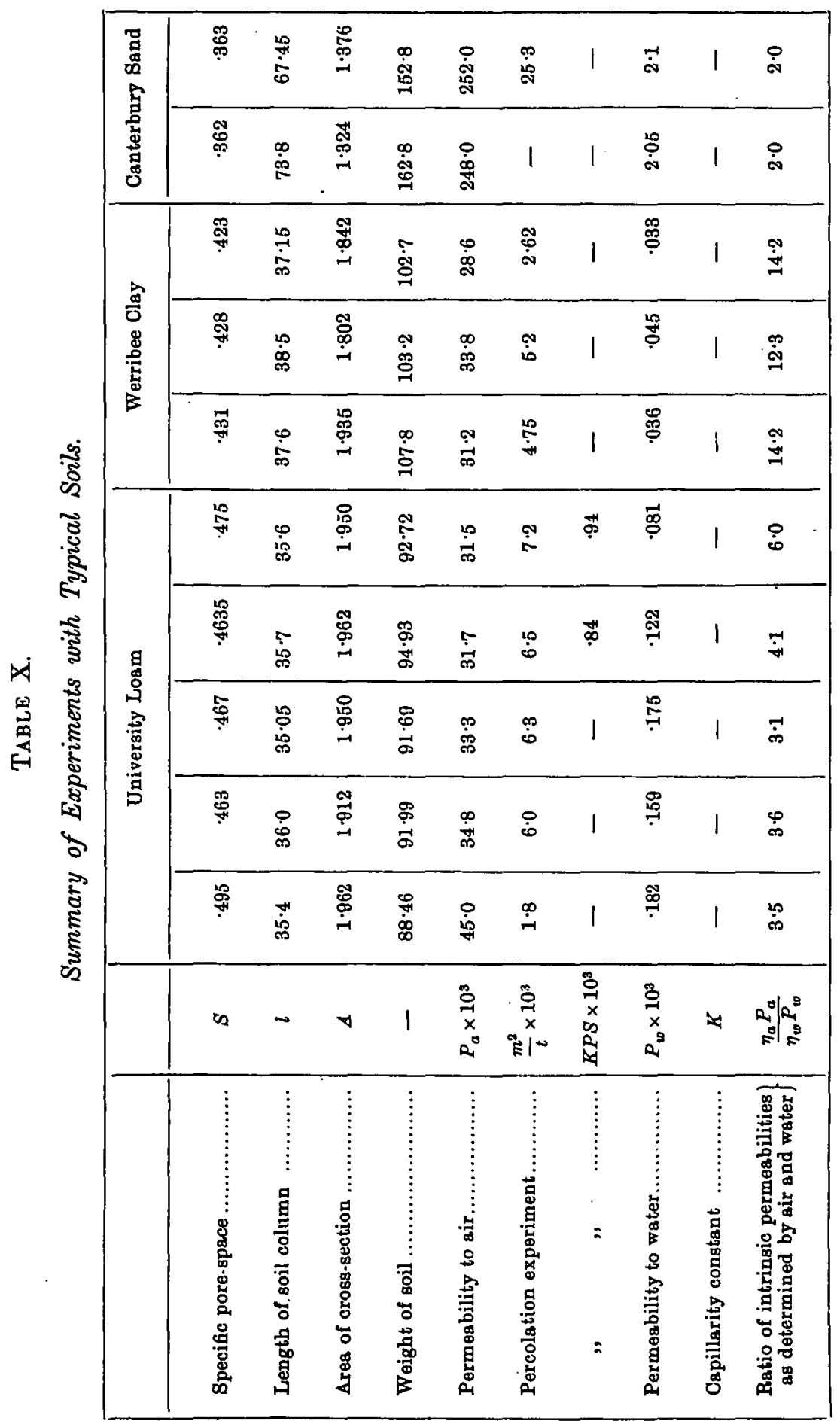


the permeability as well as the average specific pore-space of the column.

$\$ 32$. In considering these tables of results it must be borne in mind that none of the soils were in their natural condition; e.g. the loam samples had, with one exception, been dried and contained no moisture at the start of the experiment, whilst the clay had been airdried and only contained 2.0 per cent. of water, and the sand had also been partially dried.

Notwithstanding this the different soils differ markedly in their constants, thus one characteristic feature shewn by the clay soils is the high value given for the ratio $\frac{\eta_{a} P_{a}}{\eta_{v 0} P_{v}}$, indicating that the water has the effect of swelling out the colloidal matter in the soil and so constricting the capillary passages. This ratio should be unity for soils composed of pure sand; experiments, on that medium and on glass beads, to be described in a subsequent paper, have given identical results for $\frac{\Sigma r^{t}}{A}$, whether calculated from $P_{a}$ or $P_{w}$ (vide $\$ 9$ ).

$\$ 33$. Whilst more valuable when carried out on a natural soil in situ, these measurements of the percolation factors can also yield considerable information when applied to disturbed samples of soil, such as are ordinarily sent in to the laboratory for " analysis."

Only about one hundred grams are required, and it is suggested thit the soil should be prepared by careful air-drying, and reducing to powder with a rubber pestle in the usual way when in a friable condition. The soil tube should then be packed as tightly and uniformly as practicable with this air-dry soil after all particles larger than .1 mm. in diameter have been removed.

\section{Sommary.}

\$34. 1. The permeability and capillarity constants of soil have been defined.

2. The movements of air and water through three types of soil have been measured and shewn to conform to equations connecting the rate of motion with the above constants.

3. It is suggested that the mensurement of $S, P_{a}, P_{w}$ and $K$ is of more importance than, and should replace, the determination of the sizes of the soil particles as in the usual "mechanical analysis" of soils.

In conclusion, we have to acknowledge our indebtedness to Professors T. R. Lyle and R. J. A. Barnard for valuable advice and suggestions and to the Victorian Government for financial assistance towards the expenses of this research. 